\title{
EXPERIMENTAL BEHAVIOR AND DESIGN OF RECTANGULAR CONCRETE- FILLED TUBULAR BUCKLING-RESTRAINED BRACES
}

\author{
Yan-Chao Yue ${ }^{1}$, Yong-Tao Bai ${ }^{2,}{ }^{*}$, Yan Wang ${ }^{1}$, Xiao-Fei Ma ${ }^{3}$, Yu-Hang Wang ${ }^{2}$ and Xiao-Hua Li ${ }^{2}$ \\ 'Department of Civil Engineering, Xi' an Jiaotong University, Xi'an 710049, China \\ ${ }^{2}$ School of Civil Engineering, Chongqing University, Chongqing 400045, China \\ ${ }_{3}^{3}$ China Railway First Survey and Design Institute Group Co., Ltd., Xi'an 710043, China \\ *(Corresponding author: E-mail: bai.yongtao@cqu.edu.cn)
}

\section{A B S T RA C T}

This paper proposes a new design method for concrete-filled tubular buckling-restrained braces (CFT-BRBs) by ncorporating the confinement effect on pre-buckling rigidity. A series of experiments are performed to investigate the effects of concrete strength and sectional dimension on the initial stiffness, ultimate strength, and energy di ssipation behaviors. Experimental results indicate that the confined concrete plays an important role in the energ y dissipating capacity of CFT-BRBs. On the other hand, the sectional dimensions of the steel tube and core are influential factors governing the ultimate failure modes of CFT-BRBs. The findings in study provide technical su pports to optimize the design methods for ductile seismic performance of CFT-BRBs in low-rise and high-rise st eel buildings.
A R T I C L E H I S T O R Y

$\begin{array}{ll}\text { Received: } & \text { 25 January } 2021 \\ \text { Revised: } & 27 \text { May } 2021 \\ \text { Accepted: } & 28 \text { May } 2021\end{array}$

\section{K E Y W O R D S}

Buckling-restrained braces; Concrete-filled steel tube; Buckling mechanism; Cumulative plastic deformation Energy dissipation;

Performance-based design

\section{Introduction}

Buckling Restrained Braces (BRBs) as structural control dampers with stable performance and good energy dissipation effect, have been widely used in building engineering practice across the world. The earliest idea on BRBs can be traced back to the 1960s in the case of steel braces enclosed by the reinforced concrete shear wall $[1,2,3]$. Afterwards, the prototypical BRBs were developed by the Tokyo Tech and Nippon Steel in 1988 [4-9]. The initial design for a BRB typically includes a core steel element and an external restraining system. The core steel element, which is the energy-dissipating element, generally consists of a thin-plate section, cross-section, or H-section. The external restraining component such as hollow or concrete-filled steel tubes, restrains the inner core from losing its overall stability to ensure its strength capacity. Between the core steel member and the external restraining system, an un-bonded material is set so that the core steel and external restraining system can be fully isolated and maintain a certain gap. This treatment not only provides deformation space for the expansion of the core section caused by the Poisson effect, also eliminates the adverse effects caused by friction.

In recent years, several scholars around the world have carried out in-depth and comprehensive research on buckling restrained braces from the aspects of structure configurations, material properties, engineering applications, and mechanical properties. In terms of structural configuration, Zhu et al. [10] developed a core-separated BRB, called corrugated-web connected bucklingrestrained brace (CWC-BRB), which has much larger flexural stiffness and load-carrying capacity compared to ordinary single-cored steel BRBs [10, 11]. Wang et al. [12] proposed a brace with partial buckling restraint, called the partially buckling-restrained brace (PBRB), which is designed for quick damage evaluation of BRBs after earthquake without disassembling the restraining members. Xie et al. [13] proposed a sandwiched BRB that eliminated the use of unbonded materials, where the core plate could be replaced independently of the restraining members after a large earthquake. Tsai et al. [14] proposed double-tube BRBs that adopt double tee to gusset plate connections, which can reduce the length of the connection. From the point of view of material properties, Hu et al. [15] reviewed the SMA-alloy buckling-restrained braces due to the advantages of aluminum and its alloys that include being lightweight, corrosion resistance and economic and environmental benefits. Wang et al. [16] studied the effects of different un-bonded materials on the mechanical properties of buckling restrained braces. The application and seismic response of BRBs in structures or frames are also investigated using experimental examinations or numerical simulations by many researchers $[17,18,19]$.

From the mechanical properties of braces, suitable buckling restrained braces must satisfy the following conditions [20]:

- They should have a good hysteretic curve to ensure that braces do not suffer from overall instability under tension and compression cyclic loads, and the restrained element must have sufficient flexural stiffness and strength. Many researchers have conducted in-depth studies about the overall instability of BRBs and proposed many formulas for design purposes [21, 22, 23].

- The steel core element should not suffer from local instability under the designed axial force and deformation. [20, 24-32].

- The connection joints should have sufficient stiffness to ensure that the braces do not suffer from overall instability under the designed axial force and deformation [33].

However, in the previous studies on the mechanical properties of braces, restraining effects of filled concrete on core steel are neglected or given an approximate reduction factor, without considering the influence of the strength and stiffness of concrete on the overall stability. Compared to the all-steel buckling restrained braces, the concrete pairs in the filled buckling restrained braces are different from those in the all-steel buckling restrained braces. The energy dissipation capacity plays an important role in the hysteretic behavior of buckling restrained braces. The question of how to reasonably consider the effect of concrete on the mechanical properties of buckling restrained braces to reduce the size of restrained members with economical and reasonable filled buckling restrained braces provides invaluable theoretical and engineering values. For those purposes, several groups of specimens are designed to study the influence of concrete strength and section dimensions on the mechanical performance of BRB.

\section{Evaluation of failure criteria of concrete-filled tubular BRBs}

\subsection{Overall buckling of CFT-BRBs}

The mechanism of BRB's overall stability is shown in Fig. 1. The core plate generally loses its overall stability before yielding when the restraint member cannot provide sufficient stiffness. It is assumed that the tangential friction between the core plate and concrete is zero, the tube and concrete are tangentially non-slippery, the length of the core material and restraint tube is equal, and the restraint tube has no initial defects. The initial defect of core steel thus is:

$v_{0}=2 \times g \times \sin \left(\frac{\pi x}{l}\right)$

where $v_{0}$ is the initial imperfection, $g$ is the lateral gap between the steel core and outer tube, $l$ is the buckling length of the outer tube, and $x$ is the distance from the specified brace cross-section to the end, respectively. In Eq. (1), the shape of the first-order buckling mode is adopted for the imperfection 
deformation, which is correlated with the numerical results of the finite element analysis. It is usually reasonable to define the gap width as twice that of the imperfection amplitude so that the moment and deformation of "one point contact" between the steel core material and concrete infill can be regarded as the initial imperfection.

According to the static equilibrium method, as shown in Fig. 2, the bending moment equilibrium based on the position of the neutral axis of the core section is given in Eq. (2). The inertia moment of the core plate to the neutral axis is extremely small, and the tangent modulus of the steel after yielding is generally only $1 \%$ to $2 \%$ of the elastic modulus. Therefore, to simplify the model, the bending stiffness of the core plate is ignored.

$E I \frac{d^{2} v}{d x^{2}}+\left(v+v_{0}\right) P_{\max }=0$

$E I=E_{b} I_{b}+\alpha E_{c} I_{c}$

where $P_{\max }$ is the ultimate axial force of core plate; $v$ is the transverse deflection deformation of steel tubes; $E$ is the elasticity modulus; $I$ is the inertial moment; $E_{b}, I_{b}$ are the elasticity modulus and inertial moment of steel tubes, respectively; $E_{c} 、 I_{c}$ - elasticity modulus and inertial moment of filled concrete and $\alpha$ is stiffness reduction factor of concrete. For simplicity, by assigning $k^{2}=P_{\max } / E I$ Eq. (2) can be written as:

$v^{\prime \prime}+k^{2} v=-k^{2} v_{0}$

The general solution of Eq. (4) can be stated as:

$v=C_{1} \sin k x+C_{2} \cos k x$

Assuming the special solution is:

$$
v^{*}=C_{3} \sin \frac{\pi x}{l}
$$

Substitute Eq. (1) into Eq. (4), we get:

$$
-\frac{\pi^{2}}{l^{2}} \cdot C_{3} \sin \frac{\pi x}{l}+k^{2} \cdot C_{3} \sin \frac{\pi x}{l}=-k^{2} \cdot 2 g \sin \frac{\pi x}{l}
$$

Substitute the formula ( $P_{E}=\frac{\pi^{2} E I}{l^{2}}$ ) into Eq. (7), then we can get Eq. (8):

$-\frac{P_{E}}{E I} \cdot C_{3} \sin \frac{\pi x}{l}+\frac{P_{\max }}{E I} \cdot C_{3} \sin \frac{\pi x}{l}=-\frac{P_{\max }}{E I} \cdot 2 g \sin \frac{\pi x}{l}$

From the above equation, we can obtain $C_{3}=\frac{2 g}{\frac{P_{E}}{P_{\max }}-1}$, so the general solution of Eq. (2) is:

$v=C_{1} \sin k x+C_{2} \cos k x+\frac{2 g}{\frac{P_{E}}{P_{\max }}-1} \sin \frac{\pi x}{l}$

Considering the boundary conditions: $(0)=0, \quad(l)=0$, we can get $C_{1} \operatorname{sinkx}=0, C_{2}=0$. Since $P_{\max }<P_{E}$, so $\operatorname{sinkl} \neq 0, C_{1}=0$. Eq. (9) can be written as:

$v=\frac{2 g}{\frac{P_{E}}{P_{\max }}-1} \sin \frac{\pi x}{l}$

The mid-span bending moment of the BRB is:

$M_{c}=\frac{2 g \cdot P_{\max }}{1-\frac{P_{\max }}{P_{E}}}$

where $M_{c}$ is the mid-span bending moment of BRB components. The maximum stress at the edge of the mid-span section of the steel tube is: $\sigma_{\max }=\frac{M_{c} H}{2 I}=\frac{g H P_{\max }}{I\left(1-\frac{P_{\max }}{P_{E}}\right)}$

where $H$ is the height of steel tube.

Since the first-order Euler force is $P_{E}=\frac{E I \pi^{2}}{l^{2}}$, Eq. (12) can be written as:

$\sigma_{\max }=\frac{M_{c} H}{2 I}=\frac{E \pi^{2} g H P_{\max }}{P_{E} l^{2}\left(1-\frac{P_{\max }}{P_{E}}\right)}=\frac{E \pi^{2} g H}{l^{2}\left(\frac{P_{E}}{P_{\max }}-1\right)} \leq f_{y}$

$\frac{P_{E}}{P_{\max }} \geq 1+\frac{E \pi^{2} g H}{f_{y} l^{2}}$

$\frac{P_{E}}{P_{y p}} \geq \omega\left(1+\frac{E \pi^{2} g H}{f_{y} l^{2}}\right)$

where $f_{y}$ is the yield strength of steel tube; $P_{y p}$ is the yield axial force of core plate; $\omega$ is the strain hardening coefficient.
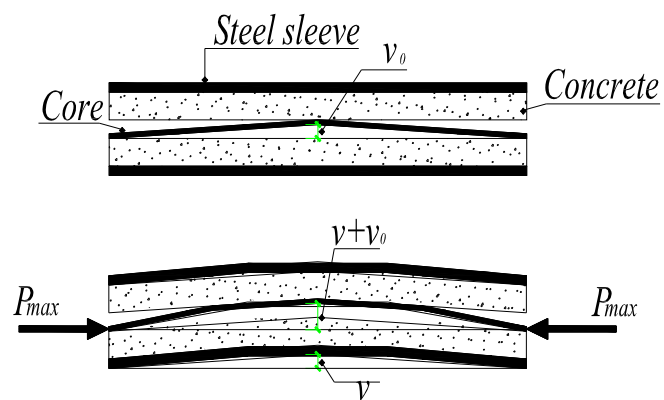

Fig. 1 Schematic diagram of overall stability mechanism of buckling restrained braces

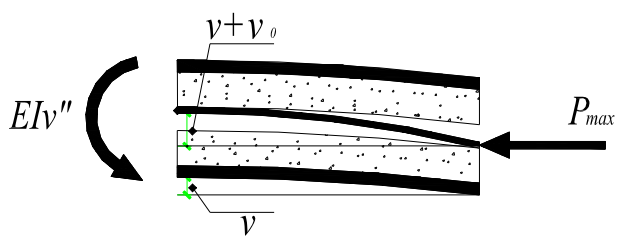

Fig. 2 Schematic diagram of the static equilibrium method

\subsection{Local buckling of CFT-BRBs}

By satisfying the formula about the constraint ratio limit of tube stiffness, the overall instability of CFT-BRBs can be avoided theoretically. However, this cannot prevent the local buckling of the steel core.

Takeuchi et al. [20, 24, 34] concluded that when the restraint tube can provide sufficient stiffness, the steel core change from first-order buckling to higher-order buckling until the core plate yields. At this moment, the wavenumber does not change and the wavelength decreases. Based on these assumptions, the formula of half-wavelength buckling and the magnitude of local extrusion force is given, and then the local bearing capacity of the restrained member is checked.

Assuming that the wavenumber of the core plate remains unchanged after yielding, with the increase of axial deformation following phenomenon occurs: - The axial load will be further strengthened due to strain strengthening

- The wavelength of buckling will be further shortened, and

- The local extrusion force will be further increased.

Therefore, for the energy dissipation of the BRB, the ultimate load should be considered as the most disadvantageous condition to check the local bearing capacity.

In Fig. 3 (a), when the core yields, the wavenumber does not increase anymore. Based on the theoretical hypothesis of Takeuchi et al. [20, 24, 34], the inner core segment between adjacent contact points, as shown in Fig. 3 (b), can be regarded as a stress formula conforming to the eigenvalue buckling. Here, the length of the inner core segment between adjacent contact points is defined as the buckling half-wavelength. According to the static equilibrium relation of Fig. 3 (b), the thrust is solved by combining Eqs. (15) and (16): 
$P_{b}=\frac{2 P_{\max }\left(2 g+v_{p} \varepsilon_{\max } t_{p}\right)}{L_{w}}$

where $v_{p}, t_{p}$ and $\varepsilon_{\max }$ are the plastic Poisson's ratio $v_{p}=0.5$, the thickness of the core plate, and the maximum tensile strain of the core plate, respectively. $L_{w}$ is the total wavelength which can be predicted as follows $(28,29,33)$ :

$L_{w}=\pi t_{p} \sqrt{\frac{E_{t p}}{3 f_{y p}}}$

where $E_{t p}$ is the tangent modulus of the core plate, and $f_{y p}$ is yield stress of the core plate.

Eq. (15) gives the local bearing demand of restrained members under the ultimate load. To solve the local resistance of constrained members, a simplified model of local resistance of constrained members should be established first as seen in Fig. 4, the plastic hinge design theory is adopted here.

When the thrust of the steel core plate to sleeve exceeds a certain value, the concrete will be fractured along the oblique section and lose its shear resistance. The load will spread to the inner surface of the steel tube. When the local bearing capacity of the steel tube is insufficient, plastic hinges will appear at the boundary of uniform load and the support seat, which is the four-hinged yield mechanism (as shown in Fig. 4 (a)). On the other hand, as for large width of the steel core plate, the steel tube is subjected to uniformly distributed loads creating plastic hinges in the middle of span and support hence forming a three-hinged yield mechanism (Fig. 4(b)). Kishiki [35] and Junxian Zhao et. al [36, 37] pointed out that the failure criterion of resistance should be the edge yield of restrained members. However, the failure criterion of local resistance of buckling restrained braces is different from the edge yield criterion of global instability.

CFT-BRBs can continue to work until irreversible plastic deformation occurs on the sleeve surface. Therefore, the failure criterion of the sleeve plastic hinge forming mechanism is proposed in this paper.

In Fig. 4(a), according to the plastic hinge theory, the ultimate lateral resistance of the steel tube can be given as follows:

$M_{\max }=\frac{q B\left(B_{c}+2 a t_{c}\right)}{24}\left(3-3 \frac{B_{c}+2 a t_{c}}{B}+\frac{\left(B_{c}+2 a t_{c}\right)^{2}}{B^{2}}\right) \leq M_{p}$
$M_{p}=\frac{B t^{2}}{4} f_{y}$

$F_{R}{ }^{\prime}=q\left(B_{c}+2 a t_{c}\right)$

where $F_{R}$ ' is the lateral force resistance of tube; $t_{c}$ is the concrete thickness between core and tube; $a$ is the transfer coefficient of the oblique section, here $\mathrm{a}=1$; where: $M_{p}$ is lateral ultimate moment of steel tube; $B$ is the width of steel tube; $q$ is the uniformly distributed load, and $t$ is the thickness of steel tube.

From Eqs. (17), (18), and (19), $F_{R}$ ' can be solved as:

$F_{R}{ }^{\prime} \leq \frac{6 t^{2} f_{y}}{3-3 \frac{B_{c}+2 a t_{c}}{B}+\frac{\left(B_{c}+2 a t_{c}\right)^{2}}{B^{2}}}$

When $B \leq B_{c}+2 t_{c}$, the failure mode of steel tubes becomes the yield mechanism with three hinges, as in Fig. 4 (b), then:

$M_{\max }=\frac{q B^{2}}{12} \leq M_{p}$

$M_{p}=\frac{B t^{2}}{4} f_{y}$

$F_{R}{ }^{\prime}=q B$

Combining Eqs. (21), (22), and (23), $F_{R}$ ' can be obtained as follows:

$F_{R}{ }^{\prime} \leq 3 t^{2} f_{y}$

Once $F_{R}{ }^{\prime}<P_{b}$, the out-of-plane local buckling failure will arise. For a zigzag steel core plate, buckling is more likely to occur in the direction of the weak axis. Note that buckling in the direction of the strong axis is not covered the scope of this section.

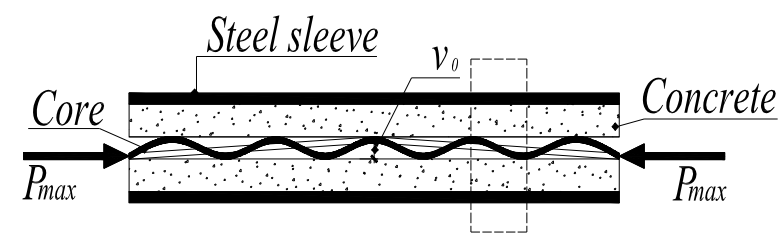

(a)

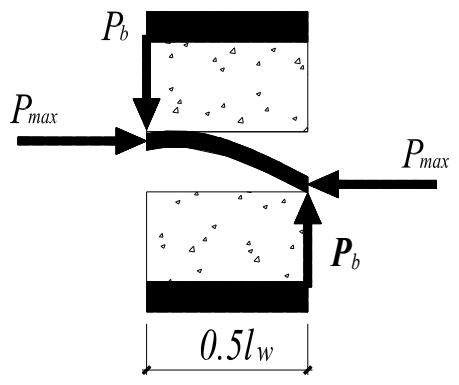

(b)

Fig. 3 Schematic diagram of buckling deformation and stress mechanism of core plate

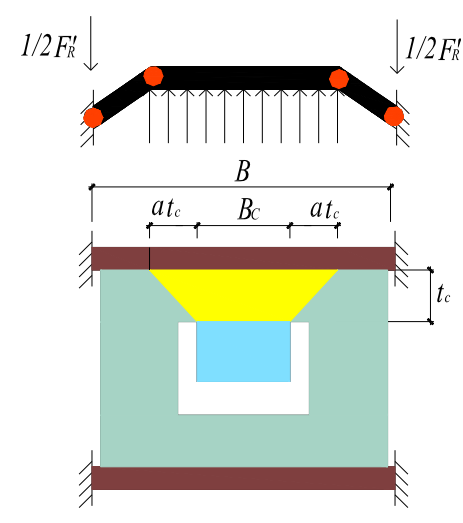

(a)

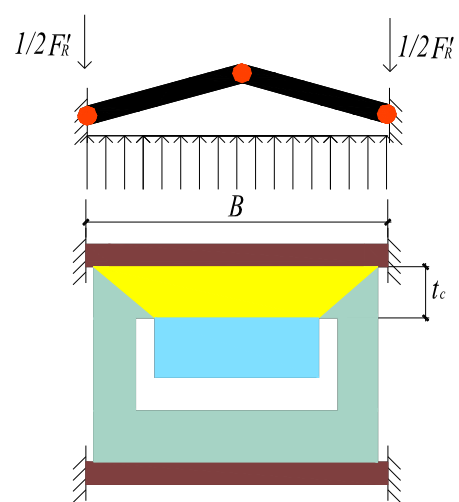

(b)

Fig. 4 The local buckling mechanism of BRB (a)with four hinges (b)with three hinges 


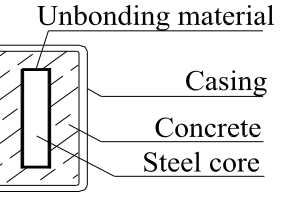

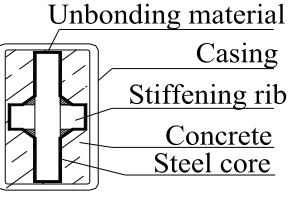

Fig. 5 Cross-section of specimens

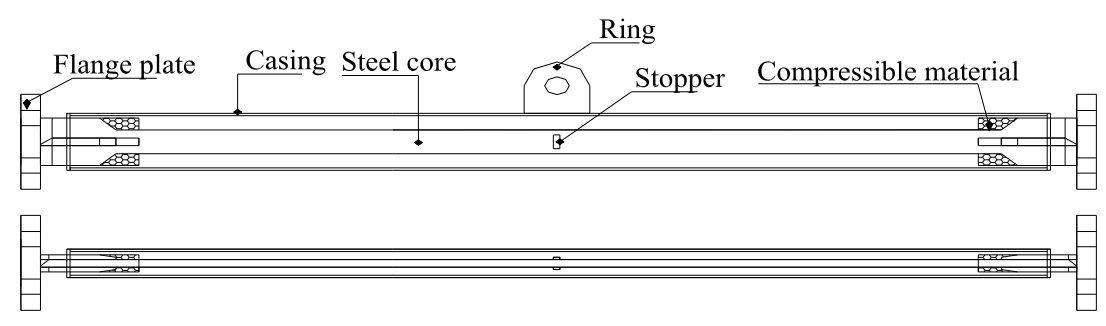

Fig. 6 The side view and top view of specimens

\section{Test program}

\subsection{Test specimen}

Eleven specimens with different dimensions and concrete strengths were designed for the test. All the core steel used is of an I-shape steel plate and wrapped with non-bonding material. It is composed of a yielding segment and steel core projections with ribs. The sleeve is made of a rectangular steel tube. The concrete material is filled between the core steel and the sleeve. The crosssection of the specimens is shown in Fig. 5. The side view and top view are shown in Fig. 6.

In this test, two core sections are examined. These core sections are $80 \mathrm{~mm}$ x $16 \mathrm{~mm}$ and $50 \mathrm{~mm} \times 16 \mathrm{~mm}$, respectively with two strength grades of Q235B and Q345B. The length of the core is $1400 \mathrm{~mm}$. A section steel pipe is used for the tube to eliminate the effect of welding on sleeve performance. The length, width, height of the tube are $1500 \mathrm{~mm}, 120 \mathrm{~mm}$, and $60 \mathrm{~mm}$, respectively, and the strength grade is Q235, with the only difference in its thickness. The concrete grades filled between the steel core and tube are H20, H40, and H60, respectively. The thickness of the un-bonded material is $1.5 \mathrm{~mm}$. The eleven specimens are named as $80 \times 16-2.75-\mathrm{H} 40-235$, where $80 \times 16$ is the cross-section of the steel core, 2.75 is the thickness of steel tube, $\mathrm{H} 40$ denotes the concrete strength grade and 235 represents the strength grade of the steel core.

The material properties of the steel used in the test are shown in table 1.
Similarly, table 2 shows the material parameters of concrete. All material parameters in table 1 and table 2 are the arithmetic mean of measured values of several test pieces.

Table 1

The material properties of the steel tube

\begin{tabular}{ccccccc}
\hline Material & $\begin{array}{c}\text { Thickness } \\
\mathrm{t}(\mathrm{mm})\end{array}$ & $\begin{array}{c}\text { Yield } \\
\text { strength } \\
(\mathrm{MPa})\end{array}$ & $\begin{array}{c}\text { Ultimate } \\
\text { strength } \\
(\mathrm{MPa})\end{array}$ & $\begin{array}{c}\text { elasticity } \\
\text { modulus } \\
(\mathrm{MPa})\end{array}$ & $\begin{array}{c}\text { Ductility } \\
\text { ratio } \\
(\%)\end{array}$ & $\begin{array}{c}\text { Yielding } \\
\text { strain } \\
(\%)\end{array}$ \\
\hline Q345B & 16 & 396.06 & 524.89 & 191386.30 & 36.28 & 0.1988 \\
Q235B & 16 & 260.91 & 417.04 & 230811.40 & 24.44 & 0.1356 \\
\hline
\end{tabular}

Table 2

The material properties of filled concrete

\begin{tabular}{ccc}
\hline Filled concrete & Flexural strength (Mpa) & $\begin{array}{c}\text { Compressive strength } \\
\text { (Mpa) }\end{array}$ \\
\hline H20 & 6.85 & 32.34 \\
H40 & 12.74 & 57.70 \\
H60 & 14.80 & 71.00
\end{tabular}

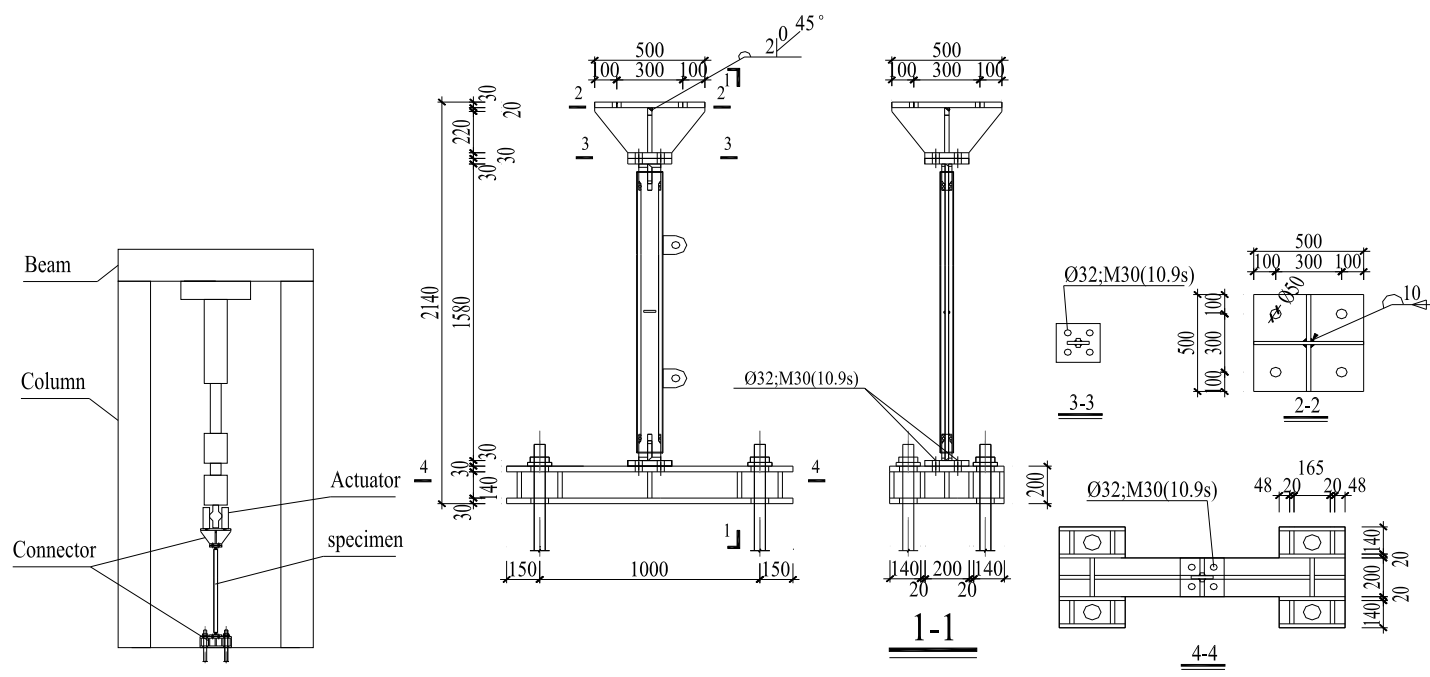

(a) Schematic diagram of BRB installation (b) Front view and side view of connectors

Fig. 7 Installation of BRB specimen

\subsection{Loading program and measurements}

According to the seismic provisions about the quasi-static test in Chinese code (JGJ/T 101-2015), horizontal low cyclical loading was applied to the top side of specimens after a constant vertical load was applied. The level of the vertical load was determined as specified in GB 50011 (2010). 
The data recorded in the experiment is the axial displacements of the specimens and the output forces of the actuator. The type of strain gauge used is the BX120-5AA metal strain gauge, and the type of displacement meter used is YHD100 displacement meter. The data of strain gauge and displacement meter are collected by a dynamic and static testing system.

To accurately obtain the axial displacement of the specimen, two pull-line displacement meters are arranged symmetrically at the connection plates and the energy dissipation section of the specimen to eliminate the influence of the bending deformation. The final displacement is averaged by the data of the symmetrical displacement gauges. Since the displacement gauge arranged at the connection plate is fixed at the specimen, it can be considered that the measured displacement does not contain the errors of bolt slip, rigid displacement, and elastic deformation of the fixed support. The positions of six displacement gauges are shown in Fig. 8.

The specimens were vertically mounted on the Material Test System (MTS) in the Civil Structure Laboratory of Shanghai Normal University. A hydraulic actuator, with a loading capacity of $1500 \mathrm{kN}$ and a displacement capacity of 100 $\mathrm{mm}$, was used for the displacement-controlled cyclic loading. Loading is divided into two steps, the first step is preloading which is used to check the reliability of all the test devices, and the second step is formal loading with a loading speed of $0.1 \mathrm{~mm} / \mathrm{s}$.

The appendix of Recommended Provisions for Buckling-Restrained Braced Frames compiled by SEAOC (Structural Engineers Association Of California) and AISC(American Institute of Steel Construction) in the United States gives a detailed description of the repeated loading requirements in support tests.

American seismic code AISC (2010) gives a detailed description of the performance test method of BRBs. Based on the test methods in AISC [38] and Zhao [33]. The loading pattern in this experiment is as follows:

All the specimens are loaded with the same quasi-static loading pattern which was divided into three stages as shown in Fig. 9.

- The nominal strain amplitude $\varepsilon$ is the axial deformation of the specimen divided by the whole length of the specimen which is $1580 \mathrm{~mm}$.

- The first stage of loading pattern was a series of variable strain amplitude (VSA) loadings with stepwise strain amplitudes $\Delta \varepsilon(1 / 1000,1 / 500,1 / 300,1 / 200$, every strain amplitude was loaded by three cycles).

- In the second stage, the constant strain amplitude (CSA) loading with a strain amplitude of $1 / 150$ was applied by 30 cycles.

- If the specimens were not damaged after the second stage, in the last stage, a series of VSA loading with strain amplitudes $\Delta \varepsilon(1 / 100,1 / 75,1 / 60,1 / 50,1 / 40$,

$1 / 35,1 / 30,1 / 25$, every strain amplitude was loaded by three cycles) until the failure of the specimens.

The loading procedures terminated when one of the following conditions occurs:

- The specimen is fractured

- The out-of-plane displacement of the specimen is too large (displacement recorded by displacement meters D2 and D3 is greater than $50 \mathrm{~mm}$ )

- The bearing capacity of the specimen decreases to $85 \%$ of the maximum bearing capacity during the third cyclic loading of the last stage deformation.

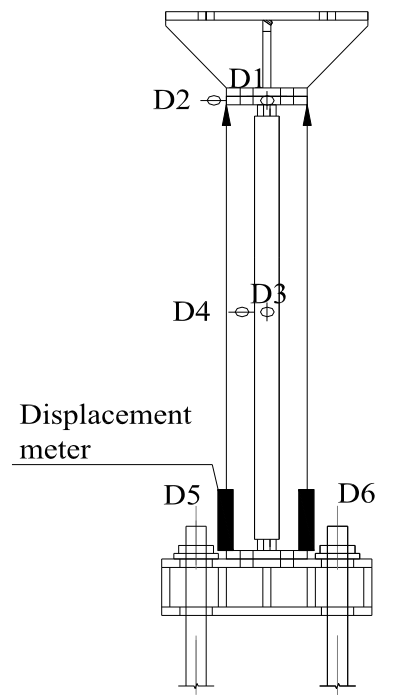

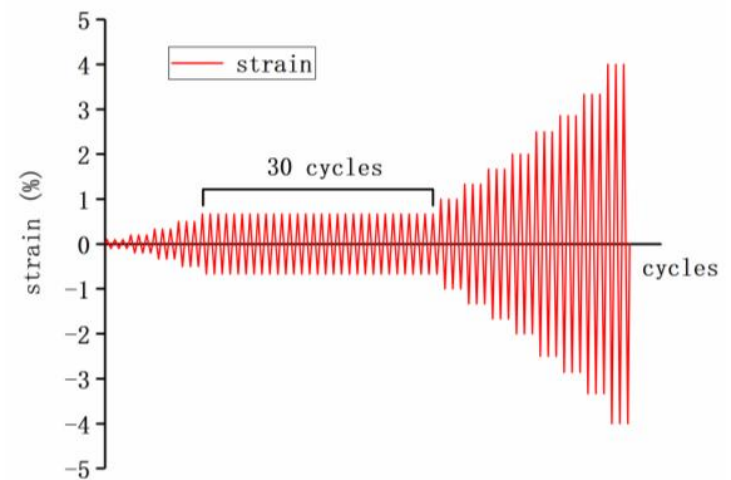

Fig. 9 The loading protocols of the test

\section{Test results}

\subsection{Hysteretic curves}

Hysteresis curves of the eleven specimens, which can be divided into two groups, are shown in Fig. 10. Figs. 10 (a), (b), (c), (h), and (i) show that hysteresis curves are full during the early loading, and then the slope of the curves abruptly change and the bearing capacity suddenly decreases, indicating that overall buckling has occurred. The hysteresis curves of the other specimens show that the specimens have local buckling during loading, and the bearing capacity and energy consumption capacity of the specimens have decreased. Among them, Figs. 10 (j) and (k) can not accurately describe the hysteretic performance of the specimens but can reflect the local buckling of the specimens during the loading process.

\subsection{Skeleton curves}

Skeleton curve refers to the envelope formed by the connection of the peak points of force and displacement in each cycle. That is, the line connecting the corresponding points of the maximum tension and compression displacement of each cycle on the hysteresis curve. The skeleton curves of the specimens are shown in Fig. 11

Fig. 11 (a1) shows the skeleton curves of CFT-BRBs with different tube thicknesses. It can be seen that the change of tube thickness has no significant effect on the initial stiffness of BRB when other parameters remain unchanged. When the loading displacement continues to increase, the differences become larger. It is shown in Fig. 11 (a1) that when the displacement is $10 \mathrm{~mm}$, both specimens reach the ultimate load, but the specimen with thicker tube exits later. This indicates that the bearing capacity of the two specimens has not reached the maximum, and is limited by the early failure of the restrained members. The stiffness of the curves in Fig. 11 (a2) changes suddenly at about $200 \mathrm{KN}$ because the local buckling of the restrained members occurs at this point.

The limit values of specimens with thinner tubes in Figs. 11 (a2), 11 (a3) and (a4) are slightly smaller than those with thicker tubes. This is because the thinner tube leads to the weak restraint capacity of the restrained members and failures in advance. It shows that the tubular thickness does not change the initial stiffness of the specimen, but affects the post-yield stiffness and load-carrying capacity of the specimen. The stiffness degradation rates and load-carrying capacity degradation rates of specimens with thinner tubes will be faster.

Fig. 11(b) shows the skeleton curves of BRB with different widths of steel cores. It can be seen from Fig.11(b) that under the same restraint conditions, specimens with large core section buckle and fail earlier than the specimen with a smaller core section. The specimen with smaller core sections are more likely to suffer local buckling failure and have a larger stiffness degradation rate.

Fig. 11(c) shows the skeleton curves of CFT-BRBs with different strength of steel core. It can be seen from Fig.1(c) that the stiffness and ultimate load of specimens with smaller core strength are smaller than those with larger core strength. Fig. 11 (d) presents the effect of concrete strength on the hysteretic behavior of BRB. The slopes of the two skeleton curves are basically the same, but the ultimate bearing capacity of $80 \times 16-2.2-\mathrm{H} 60-235$ is greater. Further combining with the test phenomenon, it is shown that the strength of the concrete affects the ultimate bearing capacity of the BRB, but does not affect its stiffness and failure mode. 

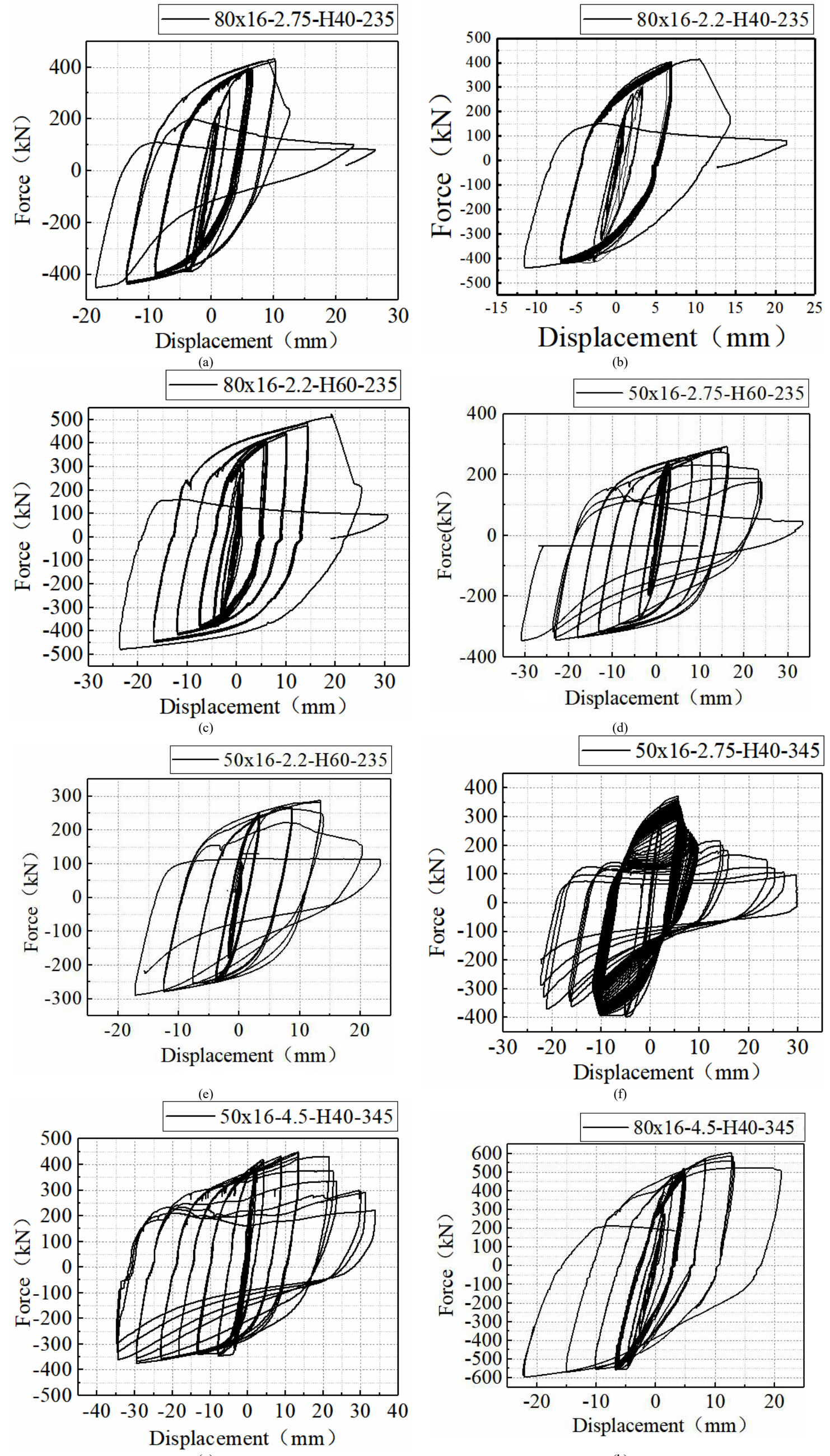

(g) 


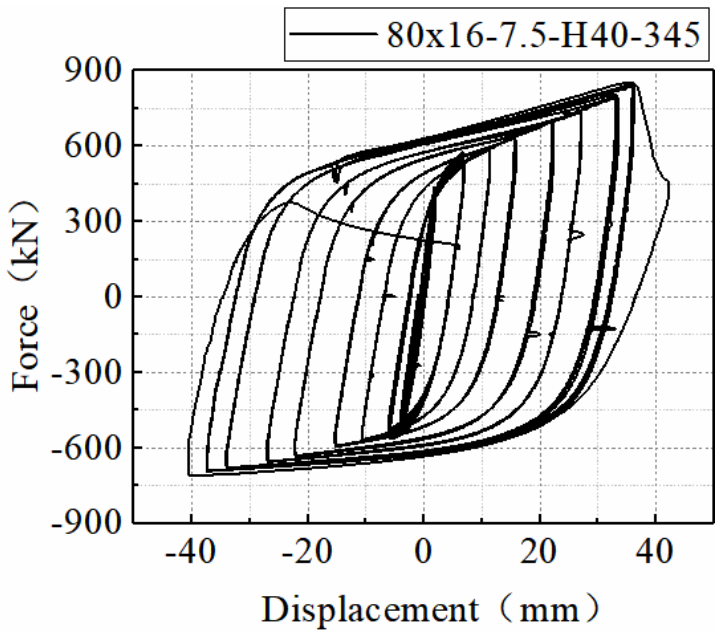

(i)

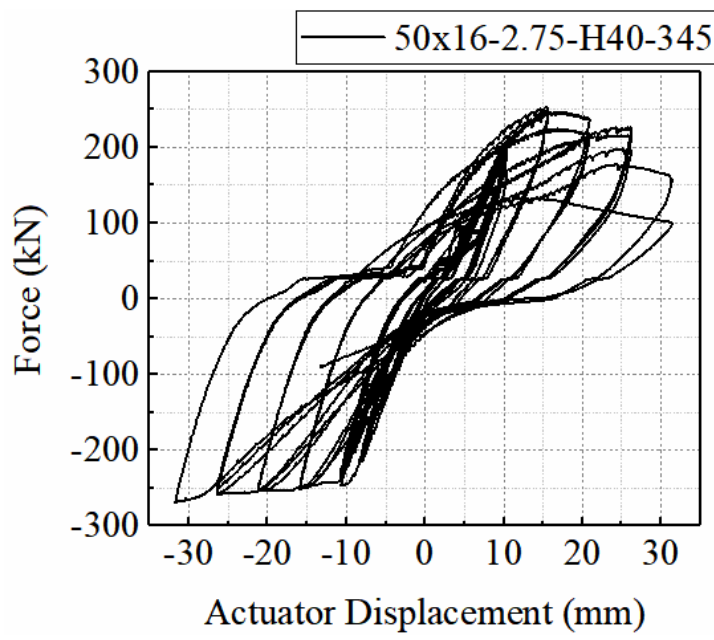

(j)

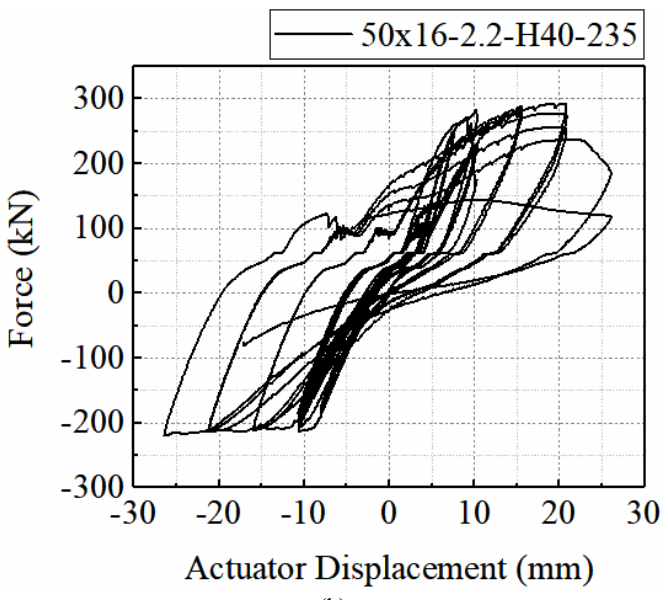

(k)

Fig. 10 Hysteretic curves of specimens
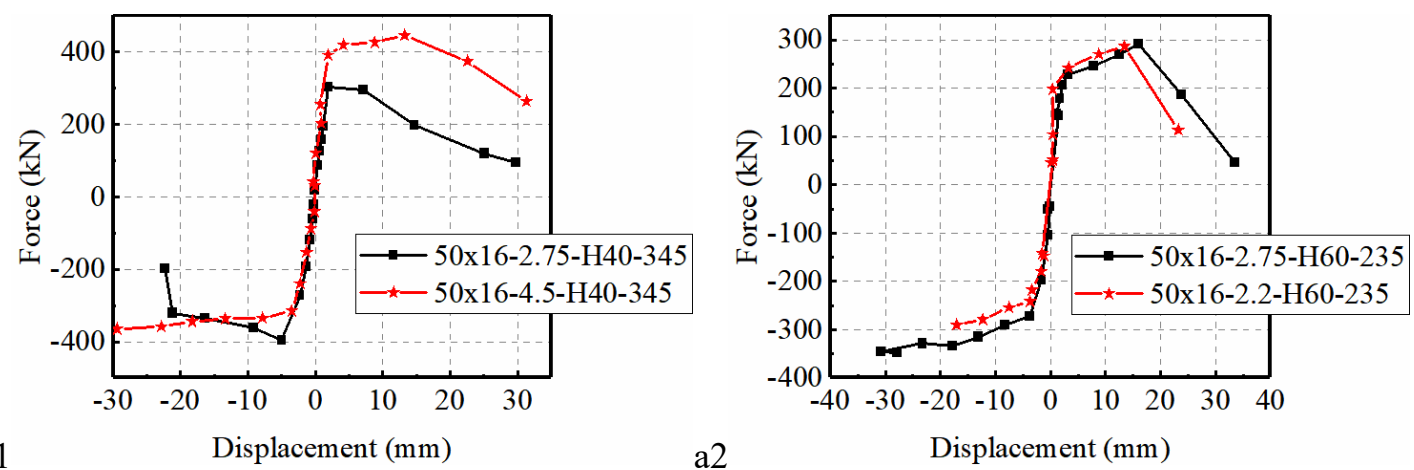

a1
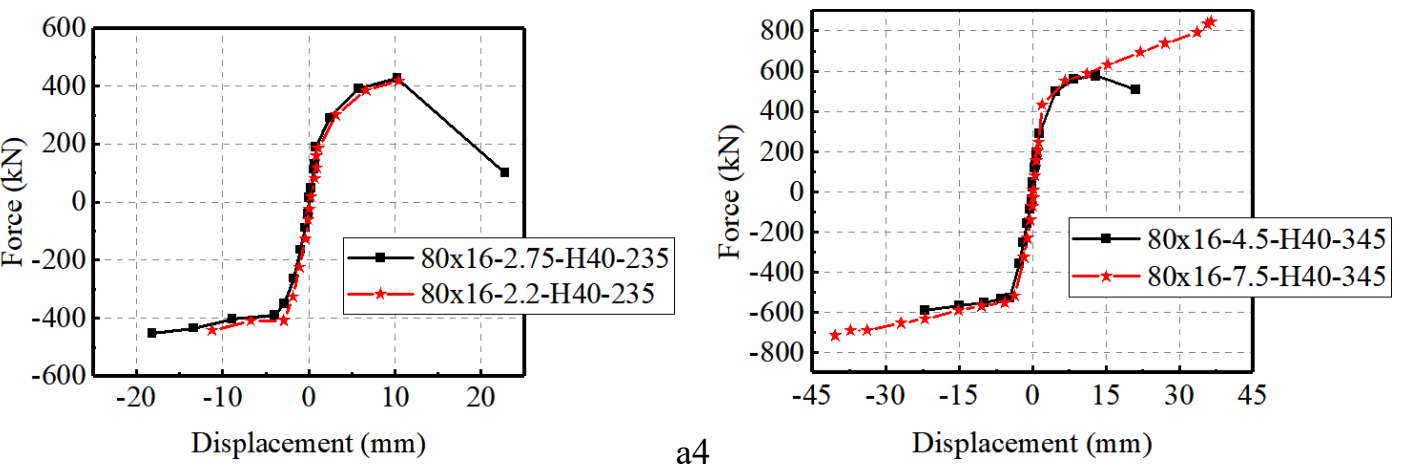

(a) Skeleton evenlop curves with various tubular thicknesses 

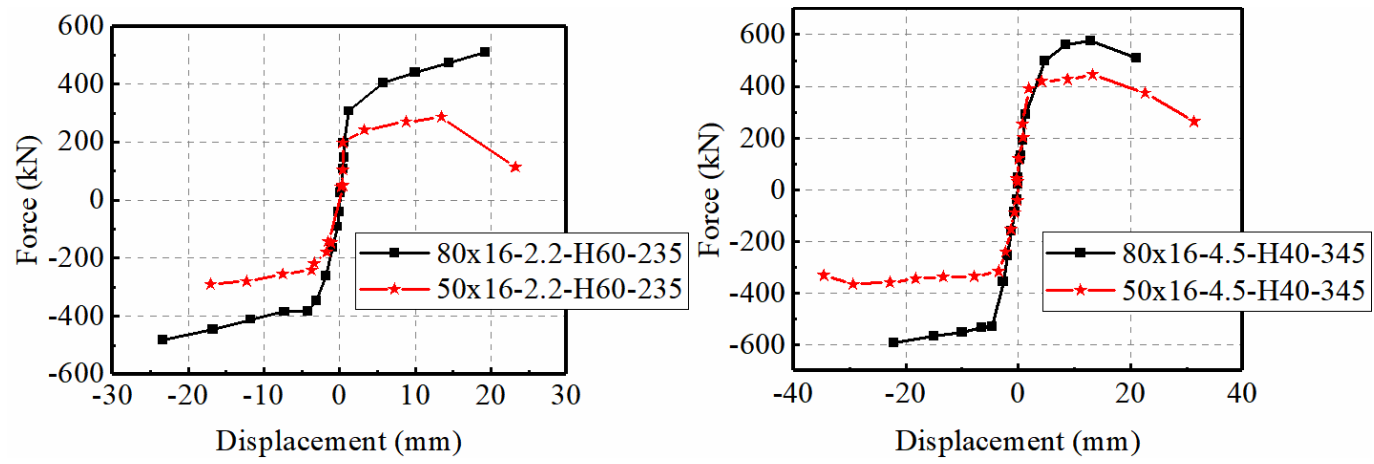

(b) Skeleton curves with various sectional dimensions

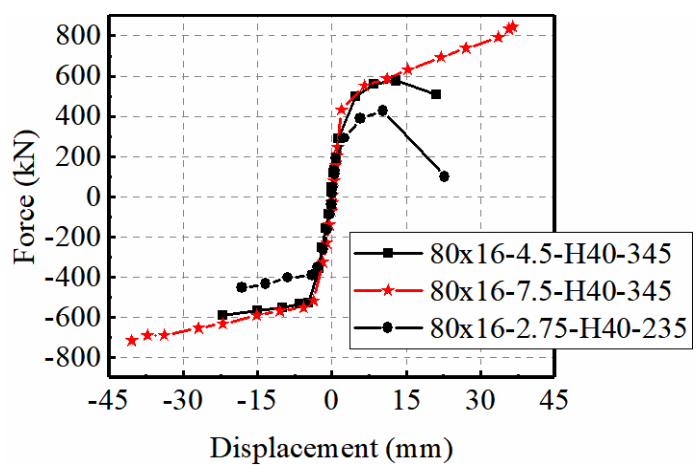

(c) Influences of steel core

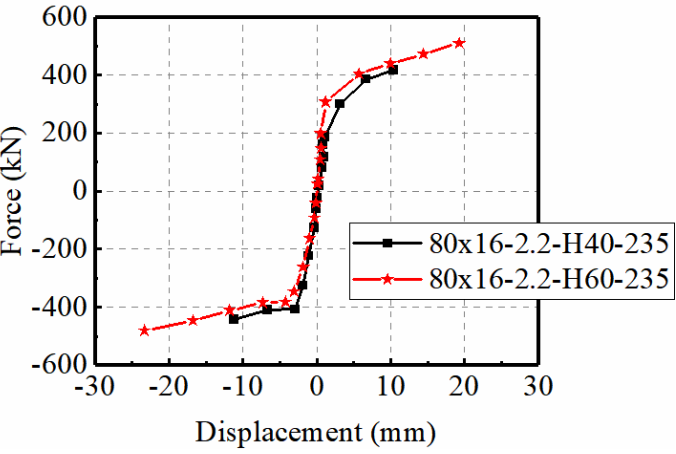

(d) Influences of concrete infill

Fig. 11 Comparisons on skeleton curves with various parameters

\subsection{Failure modes}

Based on experimental results, failure modes of the BRB specimens could be divided into three categories, A1, A2, and B. The three failure modes are shown in Fig. 12. The failure mode Type A can be identified as the overall buckling of the specimen. The overall buckling failure type can be divided into two cases: A1 and A2. The first case A1 is the overall buckling without the appearance of local buckling. During the test, the specimen yield first and then the overall buckling happens when the compressive strains were continuously applied. The failure of specimens $80 \times 16-2.75-\mathrm{H} 40-235,80 \times 16-2.2-\mathrm{H} 40-235$, and $80 \times 16-2.2-\mathrm{H} 60-235$ can be classified as type A1.

The other case $\mathrm{A} 2$ is the overall buckling initiated by local buckling. During the test, the specimen yield first and then the local buckling happens when the compressive strains were continuously applied, finally the compression force dropped significantly and the overall buckling occurs. The failure of specimens $80 \times 16-4.5-\mathrm{H} 40-345,80 \times 16-7.5-\mathrm{H} 40-345$ can be classified as type A2.

In contrast, Type B can be identified as the local buckling of the specimen when the tube is spalling and ruptured and concrete is crushed, without the occurrence of overall buckling during the test. The failure of specimens $50 \times 16$ 2.75-H60-235, 50×16-2.75-H40-235, 50×16-2.2-H40-235, 50×16-2.2-H60-235, $50 \times 16-2.2-\mathrm{H} 20-235,50 \times 16-2.75-\mathrm{H} 40-345$, and $50 \times 16-4.5-\mathrm{H} 40-345$ can be classified as type B. Table 3 shows the yield deformation of the core plates and the displacement of the specimens when buckling occurred.
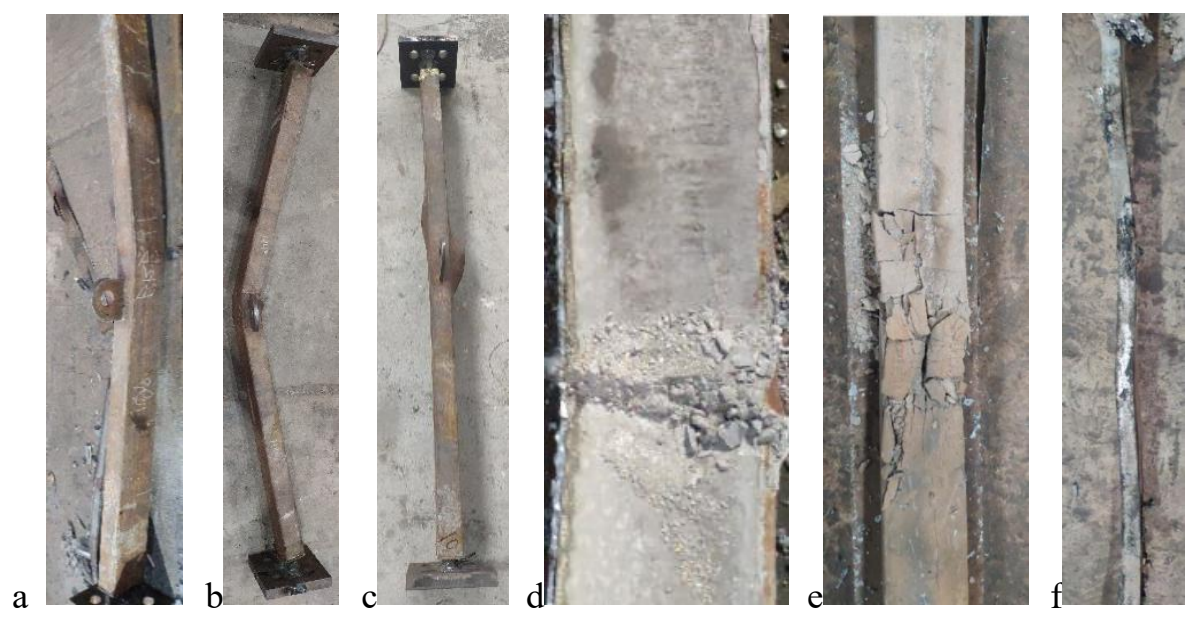

Fig. 12 (a) failure type A2 $(80 \times 16-4.5-H 40-345$, overall buckling initiated by local buckling)

(b) failure type A1 (80×16-2.75-H40-235, overall buckling)

(c) failure type B $(50 \times 16-2.75-\mathrm{H} 40-345$, local buckling in mid-span)

(d) Concrete crushing. (specimen $80 \times 16-2.75-\mathrm{H} 40-235$, overall buckling)

(e) Concrete crushing. (specimen 50×16-2.75-H40-345, local buckling)

(f) high mode buckling of steel core. (specimen 50×16-2.75-H60-235, local buckling) 
Table 3

Testing results

\begin{tabular}{|c|c|c|}
\hline Specimen name & Behavior during the test & Failure mode \\
\hline $80 \times 16-2.75-\mathrm{H} 40-235$ & The specimen yielded when the displacement was $21.07 \mathrm{~mm}$, and overall buckling happened at a displacement of $31.6 \mathrm{~mm}$. & A1 \\
\hline $80 \times 16-2.2-\mathrm{H} 40-235$ & The specimen yielded when the displacement was $21.07 \mathrm{~mm}$, and overall buckling happened when the displacement was $31.6 \mathrm{~mm}$. & A1 \\
\hline $80 \times 16-2.2-\mathrm{H} 60-235$ & The specimen yielded when the displacement was $21.07 \mathrm{~mm}$, and overall buckling happened when the displacement was $39.5 \mathrm{~mm}$. & A1 \\
\hline $50 \times 16-2.75-\mathrm{H} 60-235$ & $\begin{array}{c}\text { There were some noises heard when the displacement was } 10.53 \mathrm{~mm} \text {, and the specimen broke at the weld of the joint when the } \\
\text { displacement was } 15.8 \mathrm{~mm} \text {. }\end{array}$ & $\mathrm{B}$ \\
\hline $50 \times 16-2.2-\mathrm{H} 40-235$ & $\begin{array}{c}\text { There were some noises when the displacement was } 10.53 \mathrm{~mm} \text {, and local buckling happened at the weld of the joint when the } \\
\text { displacement was } 15.8 \mathrm{~mm} \text {. }\end{array}$ & $\mathrm{B}$ \\
\hline $50 \times 16-2.2-\mathrm{H} 60-235$ & $\begin{array}{l}\text { The specimen yielded when the displacement was } 21.07 \mathrm{~mm} \text {, and local buckling happened in the mid-span when the displacement was } \\
\qquad 26.33 \mathrm{~mm} \text {. Overall buckling happened when the displacement was } 39.5 \mathrm{~mm}\end{array}$ & $\mathrm{~B}$ \\
\hline $50 \times 16-2.2-\mathrm{H} 20-235$ & $\begin{array}{l}\text { The specimen yielded when the displacement was } 21.07 \mathrm{~mm} \text {, and local buckling happened in the upper part when the displacement } \\
\text { was } 26.33 \mathrm{~mm} \text {. The tube was spalling and ruptured in the upper part at a displacement of } 39.5 \mathrm{~mm} \text {. }\end{array}$ & $\mathrm{B}$ \\
\hline $50 \times 16-2.75-\mathrm{H} 40-345$ & $\begin{array}{l}\text { The specimen yielded when the displacement was } 21.07 \mathrm{~mm} \text {, and local buckling happened in the lower part when the displacement } \\
\text { was } 26.33 \mathrm{~mm} \text {. The compressive force suddenly reduced to } 221.5 \mathrm{kN} \text {. The concrete in the lower part was crushed and fractured. }\end{array}$ & B \\
\hline $80 \times 16-4.5-\mathrm{H} 40-345$ & $\begin{array}{l}\text { The specimen yielded when the displacement was } 15.8 \mathrm{~mm} \text {, and local buckling happened in the lower part when the displacement was } \\
21.07 \mathrm{~mm} \text {. The tube was spalling and ruptured in the upper part when the displacement was } 31.6 \mathrm{~mm} \text {. }\end{array}$ & A2 \\
\hline $50 \times 16-4.5-\mathrm{H} 40-345$ & $\begin{array}{l}\text { The specimen yielded when the displacement was } 21.06 \mathrm{~mm} \text {, and local buckling occurred mid-span in the } 24 \text { th cycle. The } \\
\text { compressive force started to reduce when the displacement was } 26.33 \mathrm{~mm} \text {. The steel core fractured when the displacement was } \\
39.5 \mathrm{~mm} \text {. }\end{array}$ & B \\
\hline $80 \times 16-7.5-\mathrm{H} 40-345$ & $\begin{array}{c}\text { The specimen yielded when the displacement was } 21.06 \mathrm{~mm} \text {, and local buckling happened when the displacement was } 21.07 \mathrm{~mm} \text { at the } \\
\text { first cycle, and overall buckling happened during the second cycle. }\end{array}$ & $\mathrm{A} 2$ \\
\hline
\end{tabular}

Table 4

Parameters for evaluating the performance of specimens

\begin{tabular}{|c|c|c|c|c|c|c|c|}
\hline Specimen & $\sigma_{\max } / f_{y}$ & $F_{R}^{\prime} / P_{b}$ & $\begin{array}{c}\begin{array}{c}L_{w} \\
(\mathrm{~mm})\end{array} \\
\end{array}$ & Axial strain & Ductility factor & CPD & $\begin{array}{c}\text { Failure } \\
\text { mode }\end{array}$ \\
\hline $80 \times 16-2.75-\mathrm{H} 40-235$ & 1.05 & 0.20 & 169 & $1.54 \%$ & 13.6 & 226 & A1 \\
\hline $80 \times 16-2.2-\mathrm{H} 40-235$ & 2.42 & 0.14 & 175 & $0.94 \%$ & 8.3 & 110 & $\mathrm{~A} 1$ \\
\hline $80 \times 16-2.2-\mathrm{H} 60-235$ & 3.63 & 0.11 & 174 & $1.86 \%$ & 16.4 & 235 & A1 \\
\hline $50 \times 16-2.75-\mathrm{H} 60-235$ & 0.61 & 0.16 & 172 & $2.58 \%$ & 22.8 & 548 & B \\
\hline $50 \times 16-2.2-\mathrm{H} 40-235$ & 0.60 & 0.16 & 172 & $1.73 \%$ & 15.3 & 204 & B \\
\hline $50 \times 16-2.2-\mathrm{H} 60-235$ & 0.58 & 0.17 & 181 & $1.66 \%$ & 14.7 & 299 & B \\
\hline $50 \times 16-2.2-\mathrm{H} 20-235$ & 0.42 & 0.19 & 172 & $1.63 \%$ & 14.4 & 354 & B \\
\hline $50 \times 16-2.75-\mathrm{H} 40-345$ & 0.68 & 0.15 & 128 & $2.13 \%$ & 10.3 & 170 & B \\
\hline $80 \times 16-4.5-\mathrm{H} 40-345$ & 0.84 & 0.28 & 128 & $1.80 \%$ & 8.7 & 94 & $\mathrm{~A} 2$ \\
\hline $50 \times 16-4.5-\mathrm{H} 40-345$ & 0.39 & 0.34 & 127 & $2.47 \%$ & 11.9 & 245 & B \\
\hline $80 \times 16-7.5-\mathrm{H} 40-345$ & 0.75 & 0.54 & 126 & $3.05 \%$ & 14.7 & 448 & A2 \\
\hline
\end{tabular}

* $\sigma_{\max }, F_{R}^{\prime}, P_{b}, L_{w}, \mathrm{CPD}$ are maximum stress at the edge of the mid-span section of the steel tube, lateral force resistance of tube, local bearing capacity of restrained members under ultimate load, wavelength, and cumulative plastic deformation respectively.

\section{Conclusions}

This paper experimentally investigates the cyclic behavior of concretefilled BRB components subjected to uni-axial loading history. The effects of concrete strength and sectional dimension on the initial stiffness, ultimate strength, failure modes and energy dissipation behaviors are evaluated by quasistatic test results of eleven concrete-filled BRB component specimens. The following conclusions can be drawn:

- The grade of concrete strength has a positive contribution to the energy dissipation behavior of CFT-BRBs. It has a positive influence on the ultimate load of BRB. The BRB filled with H60 concrete had a much higher CPD value than the BRB filled with $\mathrm{H} 40$ concrete.

- The grade of concrete strength cannot affect the final failure mode of CFT-BRBs. After the cyclic load, the concrete is crushed before the buckling of

\section{References}

[1] Sukenobu T, Katsuhiro K. (1960).” Experimental Study on Aseismic Walls of Steel Framed Reinforced Concrete Structures." Transactions of the Architectural Institute of Japan, 66, 497-500. (In Japanese)

[2] Yoshino T, Kano Y, et al. (1971). "Experimental Study on Shear Wall with Braces (Part 2)." Summaries of Technical Papers of Annual Meeting, Architectural Institute of Japan, Japanese, 11,403-404. (In Japanese).

[3] Wakabayashi M, Nakamura T, et al. (1973). "Experimental study on the Elasto-Plastic behaviour of braces enclosed by precast concrete panels under horizontal cyclic loading (part 1 and part 2)." Summaries of Technical Papers of Annual Meeting, Architectural Institute of Japan, Japanese, 10,1041-1044. (In Japanese).

[4] Kimura K, Yoshizaki K, Takeda T. (1976). "Tests on Braces encased by Mortar In-filled steel tubes." Summaries of Technical Papers of Annual Meeting, Architectural Institute of Japan, Japanese, 1041-1042. (In Japanese)

[5] Takahashi, S, Mochizuki N. (1979). "Experimental Study on Buckling of Unbonded Braces under Axial Compressive Force (Part 1 and Part 2)." Summaries of Technical Papers of Annual Meeting, Architectural Institute of Japan, Japanese, 9, 1623-1626. (In Japanese). the $\mathrm{BRB}$, so the contribution of concrete to the rigidity of the buckling restraining mechanism is suggested to be ignored from the conservative point of view.

- The cross-section dimensions of the core plate and concrete, which are important factors affecting the local buckling mechanism of steel tube, have a great influence on the failure mode of BRB. Compared with the three-hinged yield model, the four-hinged yield model is more likely to have local buckling. - The failure mode of BRB is related to its overall stability and local stability. If the overall stability is insufficient $\left(\sigma_{\max }>f_{y}\right)$, the overall buckling failure will occur without local buckling failure. If the overall stability is satisfied $\left(\sigma_{\max } \leqslant f_{y}\right)$, the failure mode should be determined according to the level of its overall and local stability.

[6] Takahashi, S, Mochizuki N. (1980). "Experimental Study on Buckling of Unbonded Braces under Axial Compressive Force (Part 3)." Summaries of Technical Papers of Annual Meeting, Architectural Institute of Japan, Japanese, 9, 1913-1914. (In Japanese).

[7] Fujimoto M. Wada A, Saeki E, et al. (1988). "A Study on the unbonded brace encased in buckling-restraining concrete and steel tube." Journal of structural and Construction engineering, 34B, 249-258. (In Japanese).

[8] Fujimoto M. Wada A, Saeki E, et al. (1988). "A study on brace enclosed in BucklingRestraining mortar and steel tube (part1)." Summaries of Technical Papers of Annual Meeting. Architectural Institute of Japan, Japanese, 10, 1339-1340. (In Japanese).

[9] Fujimoto M. Wada A, Saeki E, et al. (1988). "A study on brace enclosed in BucklingRestraining mortar and steel tube (part2)." Summaries of Technical Papers of Annual Meeting, Architectural Institute of Japan, Japanese, 10, 1341-1342. (In Japanese).

[10] Bo-Li Zhu, Yan-Lin Guo, Peng Zhou et al. (2017). "Numerical and experimental studies of corrugated-web-connected buckling-restrained braces." Engineering Structures, 134,107124 ;

[11] Bo-Li Zhu. (2018). "Theoretical and Experimental Study on Core-separated Buckling Restrained Braces with Two External Restrainers Connected by Flat Webs and Corrugated Webs." Thesis (PhD). Xi'an Jiaotong University.

[12] Chun-Lin Wang, Quan Chen, Bin Zeng, Shaoping Meng. (2017). "A novel brace with partial 
buckling restraint: An experimental and numerical investigation." Engineering Structures, $150,190-202$.

[13] Xie, L., Wu, J., Shi, J., Zhu, Y. (2020) "Influence of the core-restrained clearance on the mechanical performance of sandwich buckling-restrained braces." Advanced Steel Construction, 16(1), 37-46.

[14] TS AI K eh-Chyuan H WANG Yean-chih, WEN G Chung-shing. (2005). "Seismic Performance and Applications of Double-Tube Buckling Restrained Braces." Progress in Steel Building Structures, 7(3).

[15] Hu, J. (2013) "Design motivation, mechanical modeling and nonlinear analysis of composite PR moment frames with smart SMA connection systems.” Advanced Steel Construction, 9(4), 334-349.

[16] Quan Chen, Chun-Lin Wang, Shaoping Meng and Bin Zeng (2015). Effect of the unbonding materials on the mechanic behavior of all-steel buckling-restrained braces, Engineering Structures 111 (2016) 478-493.

[17] R. Sabelli, S. Mahin, CcHANG. (2003). Seismic demand on steel braced frame buildings with buckling-restrained braces, Engineering Structures, 25, 655-666

[18] L. Di Saeno, A.s.Elnashai. (2009). "Bracing systems for seismic retrofitting of steel frames." Journal of Constructional Steel Research, 65, 452-465.

[19] Dipti R. Sahoo, Shih-Ho Chao. (2010). "Performance-based plastic design method for buckling-restrained braced frames." Engineering Structures, 32, 2950-2958.

[20] T. Takeuchi, J.F. Hajjar, R.Matsui, K.Nishimoto, I.D.Aiken. (2012).” Effect of local buckling core plate restraint in buckling restrained braces". Engineering Structures, 44, 304-311

[21] Atsushi Watanabe, Yasuoshi Hitomi, Eiichiro Saeki, Fujimoto M. (1988). "Properties of brace encased in buckling-restraining concrete and steel tube." Proceedings of Ninth World Conference on Earthquake Engineering, Tokyo-Kyoyo 2-9 August 1988, Japan, 4, 719-724

[22] Mamoru Iwata and Masatoshi Murai. (2006). "Buckling-restrained brace using steel mortar planks; performance evaluation as a hysteretic damper." Earthquake Engineering and Structural Dynamics, 35, 1807-1826.

[23] N. Hoveidae, B. Rafezy. (2012). "Overall buckling behavior of all-steel buckling restrained braces." Journal of Constructional Steel Research, 79, 151-158

[24] Ryota Matsui, Toru Takeuchi, Jerome, F. Hajjar, Kohji Nishimoto, and Ian Aiken. (2009). "Local buckling restraint condition for core plates in buckling restrained braces." The 14th World Conference on Earthquake Engineering, Beijing 12-17 October 2008, Journal of Constructional Steel Research. 66. 139-149.

[25] Francesco Genna and Piero Gelfi (2012). "Analysis of the Lateral Thrust in Bolted Steel Buckling-Restrained Braces. I: Experimental and numerical results.” Engineering Structures, 138 (10):1231-1243.

[26] Francesco Genna and Piero Gelfi. (2012). "Analysis of the Lateral Thrust in Bolted Steel Buckling-Restrained Braces. II: Engineering Analytical Estimates.” Engineering Structures, 138 (10), 1244-1254.

[27] An-Chien Wu, Pao-chun Lin and Keh chyuan Tsai. (2014). "High-mode buckling responses of buckling-restrained brace core plates." Earthquake Engineering \& Structural Dynamics, $43,375-393$
[28] Nader Hoveidae and behzad Rafezy. (2015). "Local buckling behavior of core plate in allsteel buckling restrained braces." International Journal of Steel Structures, 2, 249-260.

[29] Giovanni Metelli,Guido Bregoli, Francesco Genna, (2016). "Experimental study on the latera thrust generated by core buckling in bolted-BRBs." Journal of Constructional Steel Research, $122,409-420$.

[30] Talebi, E., Tahir, M., Zahmatkesh, F., Kueh, A., Said, A. (2016) "Fire resistance of a damaged building employing buckling restrained braced system." Advanced Steel Construction, 14(1), $1-21$.

[31] Pao-Chun Lin, Keh-chyuan Tsai, Chieh-an Chang et al. (2016). "Seismic design and testing of buckling-restrained braces with a thin profile." Earthquake Engineering \& Structural Dynamics, 45, 339-358.

[32] Wu, A., Tsai, K., Lin, T., Tsai, C., Wang, K. (2020) "Seismic responses of RC braced frames with buckling restrained braced connected to corbels." Advanced Steel Construction, 16(1), $85-93$

[33] Junxian Zhao, Bin Wu, Jinping Ou. (2013). "Global stability design method of bucklingrestrained braces considering end bending moment transfer: Discussion on pinned connections with collars." Engineering Structures, 49,947-962.

[34] Toru Takeuchi. (2018). "Buckling-restrained brace: History, design and applications. 9th international conference on behavior of steel structures in seismic areas Christchurch." New Zealand 14-16 February 2018

[35] Shoichi Kishiki, Daisuke Uehara, Satoshi Yamada, Kazuaki Suzuki, Eiichiro Saeki and Wada Akir. (2005). "Behavior of beam splices with energy dissipating elements at the bottom flange." Journal of Structural \& Construction Engineering, 70 (597), 135-143.

[36] Junxian Zhao, Bin Wu, Jinping Ou, (2009). "The working mechanism and stability design method of anti-buckling support." Engineering Structures, 49, 947-962.

[37] Junxian Zhao, Bin Wu. (2009) "Working mechanism and stability design methods of buckling-restrained braces". Earthquake Engineering and Engineering Dynamics, 29(03), 131-139. (In Chinese)

[38] American Institute of Steel Construction. (2010). AISC 341-10, "Seismic provisions for structural steel buildings." Chicago, American.

[39] Pao-Chun lin, Keh chyuan Tsai, Kung juin wang et al. (2012). "Seismic design and hybrid tests of a full-scale three story buckling restrained braced frame using welded en connections and thin profile." Earthquake Engineering and Structural Dynamics, 41, 1001 1020

[40] An-Chien Wu, Pao-chun Lin and Keh chyuan Tsai. (2014). "High-mode buckling responses of buckling-restrained brace core plates." Earthquake Engineering \& Structural Dynamics, $43,375-393$

[39] Junxian Zhao, Bin Wu, Jinping Ou, (2009). "The working mechanism and stability design method of anti-buckling support." Engineering Structures, 49, 947-962.

[41] Junxian Zhao, Bin Wu. (2009) "Working mechanism and stability design methods of buckling-restrained braces. "Earthquake Engineering and Engineering Dynamics, 29(03), 131-139. (in Chinese) 